\title{
PFV3D: Protein Feature Visualisation on 3D structure
}

\author{
Rajiv Karbhal ${ }^{1}$, Sangeeta Sawant ${ }^{1}$, and Urmila Kulkarni-Kale ${ }^{1}$ \\ ${ }^{1}$ Savitribai Phule Pune University
}

May 6, 2020

\begin{abstract}
Mapping and Visualisation of various sequence-based features of proteins on the three dimensional (3D) structure enables to connect the sequence-space to the structure-space and thereby facilitates understanding of the sequence-structure-function relationship of proteins. Academic and commercial software programs are available for visualization and rendering of $3 \mathrm{D}$ structures but lack utilities for selection, customization, and integration of data from UniProt and PDB. PFV3D addresses these gaps and enables visualisation of features on the 3D structure using the JSmol applet.
\end{abstract}

\section{Hosted file}

PFV3D.pdf available at https://authorea.com/users/318705/articles/448614-pfv3d-proteinfeature-visualisation-on-3d-structure 